\title{
Diagnóstico de Transtorno de Déficit de Atenção e Hiperatividade (TDAH) e sua história no discurso social: desdobramentos subjetivos e éticos
}

\author{
Attention deficit/hyperactivity disorder (ADHD) \\ diagnosis and its history in the social discourse: \\ subjective and ethical ramifications
}

Diagnóstico del Trastorno de Déficit de Atención e Hiperactividad (TDAH) y su historia en el discurso social:

desdoblamientos subjetivos y éticos

\author{
Cristine Lacet" \\ Miriam Debieux Rosa**
}

\section{Resumo}

O diagnóstico de Transtorno de Déficit de Atenção e Hiperatividade (TDAH) apresentou um expressivo crescimento durante a última década, tornando-se o mais frequente dos transtornos psiquiátricos tratados em jovens. Dados epidemiológicos apontam para prevalência mundial de 4\% a 10\% entre crianças. O discurso médico contemporâneo, representado pela psiquiatria biológica e pelas neurociências, estabelece o diagnóstico de TDAH baseado na noção de déficit, incapacidade e disfunções atencional, motora e do controle da impulsividade. As disfunções são colocadas em primeiro plano e as funções psíquicas e orgânicas entendidas de maneira desarticulada entre si e em relação ao processo de constituição da subjetividade. Este artigo tem como objetivo a análise crítica do diagnóstico de TDAH, a partir do referencial teórico, ético e clínico da psicanálise, situando sua construção no discurso social, seus avanços

* Psicanalista. Doutora em Psicologia Clínica pelo Instituto de Psicologia da USP. Pós-doutoranda pela Faculdade de Educação da USP. E-mail: crislacet@yahoo.com.br

* Psicanalista. Prof. Livre docente do IP-USP onde coordena o Laboratório Psicanálise e Sociedade e o grupo Veredas - Imigração e Cultura. Prof. Titular da PUC/São Paulo onde coordena o Núcleo de Estudos Psicanálise e Política. E-mail: debieux@terra.com.br 
e influências. O diagnóstico de TDAH apresentou um deslizamento diacrônico de nomenclatura associado às ordens político-econômicas e jurídicas. A objetivação dos quadros psicopatológicos como proposta pelo DSM e pela CID-1O reduz a criança ao saber médico e à nomeação diagnóstica, excluindo sua singularidade e ocultando tanto o aspecto diacrônico de sua constituição subjetiva, como a articulação do sujeito aos traços identificatórios de sua filiação.

Palavras chave: Transtorno de Déficit de Atenção e Hiperatividade (TDAH); Diagnóstico; psicanálise.

\section{Abstract}

There has been a dramatic growth in the diagnosis of attention deficit/ hyperactivity disorder (ADHD) over the last decade, making it the most common psychiatric disorder treated among young people. Epidemiological data indicates a global prevalence of 4\% to 10\% amongst children. The contemporary medical discourse, represented by biological psychiatry and the neurosciences, establishes the diagnosis of ADHD based on the notions of deficit, disability, and attention, motor and impulse control disorders. Dysfunctions are placed at the forefront and the psychic and bodily functions studied in a disjointed manner with each other and in relation to the subjectivity process. This article aims for a critical analysis of theADHD diagnosis, drawing on the theory, ethics and psychoanalysis clinic, and placing its construction within the social discourse, its advances and influences. ADHD diagnosis presented a diachronic slip of nomenclature associated with political, economic and legal systems. The objectification of psychopathology - as proposed by DSM and ICD-1O - reduces the child to a mere subject of medical knowledge and diagnostic nomination, excluding his/her uniqueness and hiding both the diachronic aspect of his/her subjective constitution, and the subject's connection with his/herfamily traits.

Keywords: Attention deficit disorder and hyperactivity disorder (ADHD); Diagnosis; psychoanalysis.

\section{Resumen}

El diagnóstico del Trastorno de déficit de Atención e Hiperactividad (TDAH) presentó un crecimiento expresivo a lo largo de la última década, convirtiéndose así, en el trastorno psiquiátrico tratado más frecuente en jóvenes. Datos epidemiológicos muestran una prevalencia mundial de $4 \%$ a 10\% en niños. El discurso médico contemporáneo, representado por la psiquiatría biológica y por las neurociencias, establece el diagnóstico del TDAH basado en la noción del déficit, incapacidad y disfunciones motoras, atencionales y del control de impulsividad. Las disfunciones son puestas en primer plano y las funciones psíquicas y orgánicas entendidas de forma desarticuladas entre sí y en relación al proceso de constitución de la subjetividad. Este artículo tiene como objetivo el análisis clínico del diagnóstico del TDAH, desde el referencial teórico, ético 
y clínico del psicoanálisis, ubicando su construcción en el discurso social, sus avances e influencias. El diagnóstico del TDAH presentó un deslizamiento diacrónico en la nomenclatura, asociado a las órdenes político-económicas y jurídicas. La objetivación de los cuadros psicopatológicos propuesta por el DSM y por el CID-10 reduce el niño al saber médico y a la nominación diagnóstica, excluyendo su singularidad y ocultando tanto el aspecto diacrónico de su constitución subjetiva, como la articulación del sujeto a los trazos de identificación de su filiación.

Palabras clave: Trastorno de déficit de atención e hiperactividad (TDAH); Diagnóstico; psicoanálisis.

\section{INTRODUÇÃO}

Este artigo tem como objetivo a análise crítica do diagnóstico de transtorno de déficit de atenção e hiperatividade (TDAH), a partir do referencial teórico, ético e clínico da psicanálise, situando sua construção no discurso social, seus avanços e influências.

O denominado Transtorno de Déficit de Atenção e Hiperatividade (TDAH) tem paulatinamente ganhado um lugar de destaque quando consideramos a prevalência dos quadros psicopatológicos da infância e adolescência na atualidade. Nas últimas décadas foram realizadas inúmeras investigações cientificas que tomam como objeto a prevalência do TDAH (Hora, Silva, Ramos, Pontes, \& Nobre, 2015; Polanczyk, Willcut, Salum, Kieling, \& Rohde, 2014; Rivera, 2016). Pesquisas do campo médico apontam que o diagnóstico de TDAH apresentou um expressivo crescimento desde a última década (Legnani et al., 2004; Polanczyk et al., 2014; Rivera, 2016), tornando-se o mais frequente dos transtornos psiquiátricos tratados em jovens (Rohde, Miguel, Benetti, Gallois, \& Kieling, 2004). Dados epidemiológicos apontam para prevalência mundial de 4 a 10\% entre crianças. Uma revisão sistemática sobre o tema, realizada a partir de 102 estudos de prevalência em todo mundo, estima uma prevalência de 5,29\% entre menores de 18 anos e de 6,48\% entre crianças em idade escolar (Rohde et al., 2004). Um estudo coordenado pelo Instituto Glia, com 5.961 jovens de 18 Estados do país, aponta prevalência de 4,4\% entre crianças e adolescentes brasileiros de 4 a 18 anos (Polanczyk et al., 2010). Trata-se do primeiro estudo epidemiológico sobre TDAH feito no Brasil com essa abrangência. 
Polanczyk, Arruda, Querido e Bigal (2015), num estudo com 1830 crianças de 5 a 13 anos de idade, consideram que a prevalência brasileira para TDAH gira em torno de 5,1\%, não diferindo dos dados encontrados mundialmente.

Os desdobramentos dessa epidemia diagnóstica afetam a criança nos mais diversos âmbitos, como no escolar, em que se instala a demanda de que tenha seu corpo e comportamentos disciplinados em nome do bom aproveitamento escolar, muitas vezes ocultando impasses que dizem respeito à própria instituição de ensino; e no familiar, em que pais balizados por um saber médico, que aponta para a etiologia orgânica do TDAH, percebem-se pouco implicados com os sintomas dos filhos, optando por um tratamento medicamentoso. Temos nesse caso, do lado da criança, em um só tempo, corpo, fala e angústia silenciados; via de regra ela não é escutada, mas julgada a partir de seus comportamentos. O desejo tanto do lado da escola como do da família é silenciar a criança e "sua agitação".

A resposta a esse "não saber o que fazer para silenciar os comportamentos dessa criança” vai ser procurada junto ao saber médico-científico que, consoante à lógica do discurso capitalista de mercados, que tende a simplificar para gerir, tem uma resposta clara e objetiva: trata-se de um transtorno neurobiológico que deve ser tratado via medicação e terapia cognitivo-comportamental.

Essa resposta satisfaz à demanda dos pais e da escola: os primeiros sentem-se aliviados por não precisarem se perguntar sobre sua implicação nos sintomas do filho e a segunda encontra um caminho que exige menos trabalho e compreensão, eximindo-se do questionamento sobre como lidar com essa "criança que perturba".

O que se evidencia nesse caso é um reducionismo acerca do sintoma apresentado pela criança, seja no âmbito médico-científico, no escolar ou na própria compreensão dos pais - esse reducionismo não é sem consequências para a criança e seu corpo, mas, sobretudo, há uma articulação que permanece oculta, aquela que engendra o saber no campo científico ao poder no campo político e econômico.

$\mathrm{O}$ TDAH tem sua etiologia atualmente associada à neurobiologia, segundo o DSM (Manual Diagnóstico e Estatístico de Transtornos Mentais). O discurso médico contemporâneo, representado pela psiquiatria biológica 
e pelas neurociências, estabelece o diagnóstico de TDAH baseado na noção de déficit, incapacidade e disfunções atencional, motora e do controle da impulsividade, articulando-os algumas vezes a problemas comportamentais no âmbito familiar. As disfunções são colocadas em primeiro plano e as funções psíquicas e orgânicas entendidas de maneira desarticulada entre si e em relação ao processo de constituição da subjetividade. O sintoma, nesse caso, equivale à doença em si e encontramos assim, as mesmas disfunções do TDAH atribuídas às mais diferentes posições subjetivas e estruturas, como autismo, psicose e retardo mental (Legnani \& Almeida, 2009).

Do ponto de vista etiológico a discussão gira em torno de pesquisas no campo das neurociências. Rohde e Ketzer (1997), a partir de estudos neuropsicológicos, sugerem alterações corticais pré-frontais e de estruturas subcorticais a elas associadas. Outros estudos investigam o sistema de neurotransmissores, sugerindo alterações dos neurotransmissores dopamina e noradrenalina, desembocando em estudos psicofarmacológicos. Segundo Werner (como citado em Legnani \& Almeida, 2009), apesar de esses estudos ainda não serem consistentes, o uso de medicação é feito atualmente em larga escala. Nesse caso, o argumento utilizado seria de que a terapêutica medicamentosa é benéfica, uma vez que os pacientes medicados sentem-se mais calmos e com maior autocontrole, sentindo-se aliviados por saberem-se portadores de um transtorno para o qual existe um tratamento.

A despeito de estudos não conclusivos acerca de uma etiologia orgânica para o TDAH, a terapêutica medicamentosa foi difundida pela mídia como uma verdade cientificamente comprovada, já fazendo parte do senso comum.

\section{O TDAH NO DISCURSO SOCIAL}

O diagnóstico de TDAH apresentou um deslizamento diacrônico de nomenclatura associado às ordens político-econômicas e jurídicas. A referência inicial à motricidade e ao ambiente (relação com o Outro) é substituída por sinais de boa ou má conduta com conotação claramente moral. A ideia de prevenção é colocada em jogo e comportamentos, sobretudo de desobediência e agressividade na criança, passam a ser preditivos 
de um futuro transtorno de conduta. Ora, qualquer atitude da criança passa a ser interpretada sob um crivo patológico, evidenciando o fato de que o diagnóstico cria a doença.

A primeira definição foi dada por Bourneville em 1897 e atribuía à instabilidade o lugar de principal sintoma de certos quadros de retardo mental leve, enquanto disfunção no par inibição-impulsividade e a descreveu como uma mobilidade psíquica e intelectual extrema que inclui suscetibilidade, irritabilidade com tendência à destruição, negligência, necessidade de vigilância contínua, sugestionabilidade e submissão às pessoas amadas.

Em 1923, após a Primeira Guerra, uma epidemia de gripe e encefalite assolou a Europa e se dispersou pelo resto do mundo. O neurologista Von Economo utilizou na Alemanha o termo hipercinético para descrever as sequelas dessa encefalite, que se evidenciavam por movimentação incessante e desordenada, incapacidade de ficar no lugar e problemas de concentração, memória, aprendizagem e consequente dificuldade de adaptação social. Em 1960 foi descrita, nos Estados Unidos e Canadá, a síndrome de crianças hipercinéticas secundária a qualquer encefalite (Bergès, 2008).

Wallon, em 1925, publica L'Enfant turbulent, fazendo articulações entre o desenvolvimento psicomotor infantil e os achados no campo da neurofisiologia; buscava diferenciar a neuropsiquiatria infantil da psiquiatria geral. Descreve detalhadamente o desenvolvimento motor em quatro fases, pareado com a maturação: estado impulsivo, emotivo, sensório-motor e projetivo. $\mathrm{O}$ ato ou a ação se desenvolvem inicialmente para a criança num campo livre e não organizado, encaminhando-se para um campo orientado e então para um campo representado, seguindo uma linha evolutiva que vai dos movimentos incoordenados aos coordenados, tendo como objetivo o aspecto simbólico ou figurativo da atividade gestual.

Wallon insiste na importância da presença, do olhar do outro e do aspecto emotivo da relação tônico-emocional mãe-criança, exemplificado pelas crises tônico-emocionais do bebê: "as trocas motoras lançam o sujeito inteiro na relação com o outro através do corpo” (Bergès-Bounes \& Forget, 2010, p. 16, tradução nossa). Descreve quatro síndromes de turbulência 
psicomotora associadas a um substrato orgânico, mas insiste na importância do meio para compreensão da gênese da hiperatividade. A turbulência estaria para Wallon no campo da normalidade.

Quem sou eu e quem eu fui para me permitir julgar o excesso vital de uma criança? Que contas devo eu a uma sabedoria culpada que me fez tornar adulto? Damos crédito para que a criança use e abuse de sua vitalidade: quem somos nós para normalizar assim nossas nostalgias infantis? (Wallon como citado em Bergès-Bounes \& Forget, 2010, p. 16, tradução nossa).

Nos anos 6o, Ajuriaguerra descreveu o quadro de instabilidade como situado num continuum entre dois polos, o endógeno e o afetivo, decorrente das desordens emocionais precoces do desenvolvimento do bebê. O primeiro seria consequência da incapacidade de frear os movimentos e o segundo reacional e dependente do meio; as manifestações corporais seriam um meio de expressão da criança, dentre as quais se inclui a hiperatividade, que podem desaparecer ou se intensificar de acordo com as reações do meio ambiente.

Os trabalhos anglo-saxões, em contrapartida, puseram relevo na etiologia orgânica das instabilidades motoras. Strauss e Lehtinen (como citados em Bergès-Bounes \& Forget, 2010), não encontrando lesão cerebral, supuseram uma disfunção cerebral mínima como responsável pela hiperatividade; tratar-se-ia de uma lesão mínima que passaria desapercebida e ainda não seria demonstrável pelo estado da ciência na época.

O percurso histórico do quadro clínico até a classificação atual remonta, nos anos 40, ao diagnóstico de Lesão Cerebral Mínima, que na década de 60 foi rebatizada como Disfunção Cerebral Mínima, em decorrência da ausência de comprovações empíricas de correlações neuroanatômicas que justificassem os sintomas apresentados. Ambas as nomenclaturas enquadram o conjunto de sintomas que compõem hoje o quadro de TDAH.

Segundo Legnani e Almeida (2008), na década de 60, nos Estados Unidos, o governo patrocinou um projeto para realização de estudos sobre desvios de comportamento e problemas de aprendizagem para responder ao questionamento da classe média sobre o fracasso escolar de seus filhos. $\mathrm{O}$ diagnóstico de Disfunção Cerebral Mínima ganhou então grande aceitação 
social, pois diferenciava as crianças assim diagnosticadas daquelas com retardo mental ou submetidas à "privação cultural". O TDAH em 1968 foi incluído no DSM II, não mais como sintoma, mas enquanto síndrome, tornando-se uma doença que deve ser tratada através da ingestão de um medicamento. Na década de 80 o DSM III propõe a separação do TDAH dos Distúrbios de Aprendizagem.

A última mudança de terminologia na França ocorreu em 2005 através da publicação de uma avaliação do INSERM (Institut Nacional de la Santé et de la Recherche Médicale), que se refere a problemas de conduta na criança e no adolescente; a referência à motricidade desaparece em nome da boa ou má conduta ou comportamento, com uma conotação evidentemente moral. As referências passam a ser, no caso da criança, desobediência, crises de cólera recorrentes e agressividade e, no caso dos adolescentes, cortes no corpo, ferimentos, fraudes e roubos, caracterizando distúrbios de conduta.

O INSERM propõe um programa de detecção precoce e prevenção já na creche e na escola maternal e, a partir da idade de 36 meses, sugere que se observe as manifestações comportamentais que assinalem o aparecimento precoce do transtorno (brigas, desobediência, etc.) inscrevendo-as no carnê de saúde da criança. É disponibilizada para esses casos uma terapia que consiste em ensinar a crianças e adolescentes estratégias de resolução de problemas, podendo ser associado, num segundo momento, um tratamento medicamentoso visando combater os comportamentos agressivos.

O uso social da noção de transtorno, assim como é proposta pelo DSM-IV e pelo INSERM, considera-o como "o estado do que cessa de estar em ordem" (Thevenot \& Metz, 2007, p. 50) e corresponde atualmente a uma disfunção específica expressa por um conjunto de comportamentos pretensamente observáveis, que devem ser reduzidos, segundo uma leitura apoiada no modelo das neurociências, por meio de medicamentos e terapia cognitivo-comportamental.

Em resposta a essa avaliação do INSERM foi redigido um manifesto, denominado Pas de zéro de conduite pour les enfants de 3 ans, que conta com duzentas mil assinaturas, que incluem nomes como os de Bernard 
Golse, Roger Misès, Elizabeth Roudinesco, Marika Bergès-Bounes, entre outros profissionais da saúde, pais, professores universitários, historiadores, etc.

O texto alerta para os riscos de se atribuir a signos como "indocilidade, heteroagressividade, impulsividade, índice de moralidade baixa, etc.", o valor de indicativos precoces de um futuro transtorno de conduta; nesse caso, qualquer atitude da criança pode ser interpretada como sinal se uma personalidade patológica, que deve ser neutralizada por medidas que associam reeducação, psicoterapia e, a partir dos 6 anos, administração de medicação psicotrópica. Isso evidencia uma abordagem determinista, baseada num raciocínio de causalidade linear, notadamente entre o TDAH e os problemas de conduta na adolescência; os fatores de risco são colocados em primeiro plano e a prevenção é tomada como prognóstico.

Estigmatizando como patológica toda manifestação viva de oposição inerente ao desenvolvimento psíquico da criança, isolando os sintomas de sua significação no percurso de cada um, os considerando como fatores preditivos de delinquência, a abordagem singular do ser humano é negada e o pensamento acerca do tratamento robotizado. (Pas de zéro de conduite pour les enfants de Trois ans, 2006, tradução nossa).

No final do texto, há um alerta quanto ao risco de derivar práticas de saúde, especialmente psíquica, para fins normativos e de controle social. Os assinantes do manifesto também se opõem à medicalização e psiquiatrização de qualquer manifestação de mal-estar social e pregam que se preserve a pluralidade de abordagens no domínio médico, psicológico, social e educativo de cuidado à criança, levando em conta a singularidade de cada uma em seu meio, terminando num apelo por um debate democrático sobre prevenção, proteção e cuidados oferecidos às crianças.

Um consenso de especialistas da área de saúde, composto por profissionais de reconhecido percurso nos campos da Psicologia, Psiquiatria, Psicomotricidade, Neurologia, Pediatria e Psicopedagogia, redigiu um documento dirigido ao Ministério da Saúde da Argentina, no ano de 2005, alertando para o número crescente de diagnósticos e tratamentos reducionistas acerca da psicopatologia na infância. 
Assim, rotula-se reduzindo a complexidade da vida psíquica a um paradigma simplificador. No lugar de um psiquismo em estruturação, em crescimento contínuo, em que o conflito é fundante e em que todo efeito é complexo, se supõe exclusivamente um déficit neurológico (Untoiglich, 2006, p. 64).

O documento aponta para o fato de que o diagnóstico de TDAH é dado muitas vezes sem se considerar o contexto escolar, familiar e sociocultural da criança, atribuído muitas vezes a crianças com quadros psicóticos, vítimas de violência, que sofreram abuso sexual ou em processo de luto. Os meios de comunicação, por seu lado, tratam do TDAH como se fosse uma epidemia, divulgando critérios diagnósticos e banalizando tanto o diagnóstico quanto o recurso medicamentoso.

Diener (2011), ao discutir as políticas públicas de saúde mental na França e o papel do Estado e dos psicoterapeutas, principalmente a partir do dispositivo clínico dos Centres Médico-Psychopédagogiques (CMPPs), considera que, dentro do contexto político-econômico atual, é cada vez mais fomentada uma clínica balizada na noção de handicap, da deficiência ou desabilidade.

Trata-se de uma convergência de interesses, por um lado do Estado, por outro da indústria farmacêutica, promovendo uma abordagem instrumental e comportamentalista do sintoma. O Estado, visando economia de recursos, propõe a criação de centros de consultas especializados. As crianças e adolescentes devem ter alta assim que houver melhora ou remissão dos sintomas; na mesma direção, para se beneficiar do serviço de auxílio destinado às crianças com dificuldade de aprendizagem, é antes necessário que ela obtenha o status de handicapé.

Nos textos de regimento dos dispositivos médico-sociais - intimamente articulados à política pública no campo da medicina - há um deslizamento do termo sintoma para transtorno e para handicapé, reinstalando uma cisão entre normal e patológico, que além de justificar práticas segregativas, desorganiza as práticas de acolhimento das crianças e seus pais. "Se o sintoma é uma invenção do sujeito, o handicap é, por estas situações, uma invenção das instituições (família, Estado, agências regionais de saúde)" (Diener, 2011, p. 31, tradução nossa). O caráter dinâmico do sintoma fica 
assim aprisionado pela instituição; à medida que o sintoma é remitido, não há mais razão para se escrever, inscrito e circunscrito pelo status de handicapé, registrado num papel para não ser esquecido.

\section{A MEDICALIZAÇÃO DA EXISTÊNCIA}

Esse processo de renomeação de quadros psicopatológicos pelos manuais de Psiquiatria acaba por suprimir a subjetividade das manifestações sintomáticas, transformando os conflitos psíquicos em processos neuroquímicos, tendo como consequência clínica imediata, como apontado por Birman (1999), uma medicalização indiscriminada da angústia. Nega-se assim a inscrição dos conflitos na história da constituição da subjetividade e na relação com o Outro; a supressão sintomática impede ao sujeito o acesso aos aspectos em relação aos quais ficou alienado.

O TDAH ganha o estatuto de doença a partir da noção de erro ou risco, que se refere à ressignificação no campo médico de um comportamento diferente como sendo desviante da média e potencialmente prejudicial à adaptação social futura da criança, podendo levá-la ao fracasso pessoal. Na medida em que é ressignificado no campo médico, começa a buscar-se uma causa para esse risco (em geral algo que atrapalha o desempenho); uma pesquisa etiológica balizada por estudos estatísticos que apontarão para uma grande probabilidade de associação dessa causa a alterações genéticas e disfunções neuroquímicas. Há nessa lógica discursiva um tratamento "natural" para normalizar esses comportamentos e igualar o sujeito aos demais, sendo a medicação o dispositivo que normaliza o corpo do indivíduo e da população.

Produz-se um corpo a ser tratado, um corpo desviante que sustente a ideia do TDAH como uma patologia reconhecida nos campos sociais e científicos, nomeando-se, assim, o excesso de atividade e a falta de atenção como indicadores psicopatológicos.

A medicalização do desvio evidencia um momento singular da evolução da cultura e da função social da medicina; o aumento do poder médico sobre a regulação de condutas e comportamentos e sua nova função de normalização psíquica constituem um novo sintoma no laço social. A 
medicalização da existência seria uma construção social e intersubjetiva que pertence (enquanto origem e função) à estrutura da cultura moderna e da doença dessa civilização (Gori \& Volgo, 2009). Medicalização da existência e mercantilização das experiências caminham juntas nesse contexto.

A saúde se torna um problema político e a política de saúde participa de uma normalização coletiva dos comportamentos erigidos na política do Estado. Massificando e uniformizando as condutas, a política de saúde pública as expropria de sua singularidade por expertises precoces do comportamento (Gori \& Volgo, 2009, p. 18, tradução nossa).

A medicina técnico-científica contemporânea que mensura, avalia, homogeneíza e randomiza suas análises e protocolos nas diversas populações exclui, por natureza, a noção de singular. Didier Sicard (como citado em Gori \& Volgo, 2009) a denomina uma medicina sem corpo; essa medicina baseada em resultados de exames de imagem, de análises biológicas, genéticas, etc., numa configuração complexa de traços abstratos, afasta-se dos sinais concretos e singulares que o saber médico produzia até então, evidenciando uma nova semiologia. Assim como a clínica médica tradicional fundamentava suas hipóteses a partir "do conhecimento histórico, indireto, indiciário e conjectural, a nova clínica médica, mais epidemiológica, abstrata, matemática, só retém os traços reproduzíveis, universais, depurados de sua matéria singular" (Gori \& Volgo, 2009, p. 103, tradução nossa). Os avanços técnicos e científicos da engenharia médica, da bioquímica molecular, da genética e da bioinformática determinam a prevalência do modelo físico-matemático em detrimento do paradigma indiciário.

Na medida em que a medicina baliza sua prática nas provas da ciência universal dos protocolos padronizados, mais ela se afasta das marcas da singularidade da palavra do paciente, esquecendo que os cuidados oferecidos ao corpo do paciente são permeados por representações culturais, pelos mitos e pelos fantasmas que convocam o sofrimento e angústia da doença.

Guarido e Voltolini (2009), referindo-se ao discurso "biologizante" acerca da condição humana, apontam para o silenciamento do sujeito/corpo e sua substituição pelo organismo. 
Nesse cenário, o saber médico circula com estatuto de verdade no âmbito leigo; a medicalização tornou-se hegemônica nos discursos, na vida, nas práticas educacionais e de saúde mental.

A crítica à medicalização refere-se à redução de problemáticas que envolvem diversos campos e disciplinas, como as ciências sociais e políticas, a psicologia e a medicina, ao domínio metodológico disciplinar exclusivo da medicina.

A medicalização foi então tomada como expressão da difusão do saber médico no tecido social, como difusão de um conjunto de conhecimentos científicos no discurso comum, como uma operação de práticas médicas num contexto não terapêutico, mas político-social. (Guarido \& Voltolini, 2009, p. 241).

Dessa forma os estados psíquicos de pensamento e julgamento são usualmente entendidos como decorrentes de processos bioquímicos, sendo naturalizada uma interferência química sobre eles. A população adere em grande escala à medicação psicotrópica, de efeito mais imediato que as psicoterapias e que aponta para o sofrimento psíquico como uma doença do organismo, sendo, portanto, dispensável articular suas razões à biografia de cada um.

Numa privação de seu valor subjetivo e político, o homem contemporâneo se vê condenado a uma série de reivindicações sociais e de consumo solitário de bens sociais, dentre os quais a sua saúde (Gori \& Volgo, 2009). Para compreender as modificações no discurso acerca do sofrimento humano é fundamental:

Colocar em jogo a intersecção das novas produções científicas com os novos procedimentos diagnósticos, o desenvolvimento e o marketing da indústria farmacêutica e a difusão, no senso comum, dos fundamentos biológicos do que é próprio do humano (Guarido \& Voltolini, 2009, p. 249).

Desde a última metade do século XX há uma crescente dependência das práticas em saúde dos produtos farmacológicos. No campo da psicofarmacologia busca-se sintetizar drogas mais específicas e com menos efeitos 
colaterais; o marketing dos psicotrópicos traz a promessa de efeitos precisos associados a sintomas específicos dos transtornos descritos nos manuais de psiquiatria.

As pesquisas sobre neuroquímica impulsionam e são impulsionadas pela indústria farmacêutica, que visa à venda de seus produtos, sendo possível articular que a lógica de mercado interfere nas escolhas e nas práticas de saúde. Nesse sentido, os psicotrópicos ultrapassam o campo cientifico e a prática médica e se apresentam como bens de consumo, que trazem a promessa de bem-estar, felicidade e realização.

O poder dos remédios do espírito, portanto, é o sintoma de uma modernidade que tende a abolir no homem não apenas o desejo de liberdade, mas também a idéia mesma de enfrentar a adversidade. $O$ silêncio passa então a ser preferível à linguagem, fonte de angústia e vergonha (Zarafian como citado em Guarido \& Voltolini, 2009, p. 251).

O objeto de consumo remédio, assim com qualquer outro objeto de consumo, na lógica capitalista opera criando necessidades que não existiam anteriormente. A necessidade, entretanto, como advertem Guarido e Voltolini (2009), funciona numa lógica desejante, que permite o deslizamento infinito na busca de objetos: "é buscando subvertê-la que a operação capitalista empreende seus maiores esforços. Isso porque pretende convencer que sempre há um objeto sob medida para você" (Guarido \& Voltolini, 2009, p. 252-253).

Quando consideramos a constituição subjetiva como é articulada pela psicanálise, temos que a passagem do registro da necessidade para o da demanda e do desejo tem como condição um silenciamento do corpo enquanto organismo. A retomada do corpo como organismo, promovida pela medicalização e biologização dos discursos, tem como desdobramento a minimização do valor do sujeito em suas experiências.

E no processo de medicalização da existência, tomar o corpo enquanto organismo e suas respectivas sensações em primeiro plano implica numa retomada artificial da lógica da necessidade: para cada organismo doente um remédio sob medida. Oculta-se, assim, o fato de que, nesse caso, quem se adapta ao objeto-medicação é o sujeito; o alívio dos sintomas é 
tomado como indicativo de cura, promovendo-se uma mudança no plano da sensação, e essa alteração sensorial mascara o mal-estar do sujeito, interrompendo a possibilidade de sua elaboração simbólica.

Fundamentada pelo discurso médico:

[...] em que o fenômeno subjetivo é visto pela lógica do funcionamento orgânico, a medicação aparece como reguladora da subjetividade, como elemento químico que reordena a desordem de um corpo não-adaptado a uma lógica discursiva que define ideais de produção e satisfação. Na contramão de uma consideração sobre a complexidade subjetiva, o saber médico atual faz parceria com a lógica do capitalismo que idealiza no consumo a fonte de satisfação irrestrita. O medicamento cai aqui como bem a consumir, atrelado ao discurso do bem-estar saudável, numa economia de puro prazer (Guarido \& Voltolini, 2009, p. 256-257).

\section{A CRÍTICA DA PSICANÁLISE À NOSOGRAFIA SEM SUJEITO}

Pereira (2007) discute os efeitos clínicos do diagnóstico sobre a subjetivação do paciente de sua queixa, no que concerne à sua implicação em relação ao quadro clínico do qual pretende ser tratado.

Enquanto instrumento técnico, o diagnóstico, ao ser assimilado pela língua cotidiana torna-se um fato social amplo e adquire um caráter performativo, o que significa dizer que o recorte nosológico da experiência humana produz efeitos sobre o sujeito e a sociedade (Pereira, 2007).

O diagnóstico, como significante oriundo do campo médico, de um Outro respeitado, acaba muitas vezes por representar o sujeito para si mesmo e para o Outro social a partir de significações próprias desse campo:

[...] prevalência da ação da natureza sobre a subjetividade, passivação, desresponsabilização, alienação do tratamento a um saber técnico [...]. Nesse sentido o diagnóstico pode funcionar apenas como um álibi muito bem consubstanciado pela autoridade médica, que tem por teor a desimplicação desresponsabilização do sujeito face às suas próprias tomadas de posição: não sou eu. É o transtorno que me faz ser assim (Pereira, 2007, p. 2).

Tomemos o exemplo clínico do autor, da mãe de um paciente de 12 anos, que na primeira consulta diz "Dr. meu filho é TDAH". Podemos 
pensar justamente que o diagnóstico toma lugar do significante que representa aquele sujeito para o outro (como se o definisse ontologicamente), tornando-se prevalente em relação a qualquer outra característica do sujeito no âmbito familiar ou sociocultural. Nesse caso, a relação mãe e filho também carrega as marcas do recorte diagnóstico. Esse processo de alienação ao significante mestre proveniente do Outro, característico do processo de constituição subjetiva, põe em marcha cadeias significantes que servirão para dar consistência e significar o sujeito. No caso acima seria o TDAH que, em detrimento do sujeito, lhe sustentaria.

Um diagnóstico não somente esclarece sobre uma doença, como também a produz, fato negado pela psiquiatria.

Infante (2011), tomando o funcionamento da prática psiquiátrica atual enquanto um dispositivo como proposto por Foucault (1978/1995), considera:

Um discurso sobre a saúde mental com referencial estritamente neurobiológico, fundado nos mediadores químicos e nas neurociências. Correlativo a esse discurso a formulação de sistemas nosológicos experimentais fundados numa psicopatologia puramente descritiva onde a participação da causalidade psíquica propriamente é nula [...], o DSM tenta dar conta de uma dificuldade estrutural da psiquiatria que é de estabelecer quadros nosológicos precisos [...], o DSM resolve essa dificuldade abdicando de qualquer formulação de doenças, que exigem uma etiologia, a não ser raras exceções, e prefere a estas as síndromes descritivas [...] suas descrições assumem um caráter de doenças objetivadas. Estas por sua vez vão gerar uma terapêutica empirista voltada para a eliminação dos sintomas [...], jamais como portadores de sentido para o sujeito (Infante, 2011, p. 66).

A objetivação dos quadros psicopatológicos como proposta pelo DSM e pela CID-10 (Classificação Internacional de Doenças - 10) reduz a criança ao saber médico, excluindo sua singularidade e ocultando tanto o aspecto diacrônico de sua constituição subjetiva, como a articulação do sujeito aos traços identificatórios de sua filiação (Vorcaro, 2011).

O diagnóstico psiquiátrico compara as manifestações da criança com aquelas catalogadas para encontrar a qual classe de transtorno ela pode ser enquadrada e, reduzindo-a a uma categoria, aponta-se o que nela 
resiste ao ideal parental e social, indicando-se a partir daí terapêuticas que a adaptem e reconduzam à normalidade, minimizando o mal-estar que produz no projeto social.

A incidência da morbidade sobre o desejo que a criança condensa constitui uma lesão que pode atingir a rede de significações nas quais a criança se estrutura como sujeito. Na medida em que a saúde é fiadora do ideal do qual um filho é a promessa, o efeito de um diagnóstico de transtorno psiquiátrico pode atingir a subjetivação da criança [...] pode decidir a estruturação do sujeito ao tornar-se o traço prevalente através do qual ele é reconhecido pelos agentes parentais e pelos agentes de seu tratamento (Vorcaro, 2011, p. 227).

A impotência representada pela doença faz balançar o saber parental acerca do filho e suspender o desejo de filho ideal e, assim deslocada da posição de filho ideal, a criança "será interpretada na coincidência com o prognóstico do especialista” (Vorcaro, 2011, p. 228). O diagnóstico vai balizar e justificar os atos e falas da criança e inseri-la no laço social a partir dessa nomeação diagnóstica, excluindo a possibilidade de ela situar-se desde sua ordem de filiação, e permanecendo encurralada nessa identificação. E quando há apagamento do sujeito pelo diagnóstico produz-se efeito iatrogênico (Silva \& Albertini, 2016).

Essa intervenção do discurso científico na família, em sua tentativa de substituir o pai, produz filiações nem sempre simbólicas. Pode-se dizer da pretensão da ciência de ordenar os outros discursos e de aparecer como um dos Nomes-do-pai. A ciência gera e modela crianças, e os efeitos dessa "verdade" contemporânea, se não alertados, podem ser desastrosos para a ética do desejo. A substituição do pai pela ciência remete à transmissão pela via de um desejo anônimo. O abandono das crianças "mimadas" da atualidade corresponderia ao abandono moral de um adulto que não consegue sustentar sua posição frente à criança, e seria justamente esse ponto que ofereceria a ela parâmetros, inclusive éticos, para se constituir como sujeito.

A crítica da Psicanálise ao discurso médico-científico incide sobre a supressão da subjetividade e da causalidade psíquica dos quadros psicopatológicos. Trata-se de uma nosografia sem sujeito (Quinet, 2009) que tem consequências teóricas, clínicas e éticas como as discutidas ao longo desse artigo. 


\section{O QUE É POSSIVEL DE SE FORMALIZER SOBRE O TDAH NO CAMPO DA PSICANÁLISE}

Uma formulação acerca do TDAH desde referencial da psicanálise parte de uma articulação entre teoria e clínica e não visa a conclusões generalistas, mesmo porque isso não seria possível quando consideramos a singularidade da transferência, mas busca, sobretudo, advertir acerca da escuta da produção sintomática de um sujeito. Não se trata aqui de dar um estatuto psicanalítico a hipótese do TDAH, mas de interrogar-nos sobre esse corpo pulsional, que enquanto suporte relacional evidencia um excesso de gozo.

Trata-se de uma escuta que pode se valer do esquema de complementaridade tórica proposto por Lacan (1961-1962) para pensar na lógica do sintoma a partir da articulação entre demanda e desejo no campo relacional da criança e do Outro, mas que não pode deixar de considerar que há um real que vai escapar ao campo da significação, real esse que comparece como o insondável de todo sujeito.

Vamos então apresentar algumas formulações que, no campo da psicanálise, articulam os sintomas psicomotores e os impasses quanto à subjetivação do corpo, o que aponta para a passagem do puro movimento para o movimento pulsional, que afeta o Outro. Temos, por um lado, uma interessante articulação que se faz entre esses sintomas que têm o caráter de se dar a ver a um Outro, que goza ao olhar, e manipular o corpo da criança e o fato da criança permanecer ligada ao Outro via olhar, o que parece evitar a angústia de sua própria aparição como sujeito, dificultando-lhe o processo de subjetivação de um corpo próprio.

Nesse sentido faz-se necessário um primeiro esclarecimento acerca do estatuto do sintoma, no caso da hipótese de TDAH temos sintomas predominantemente motores. Um sintoma com a mesma apresentação pode aparecer em diversas estruturas. Tomemos o nosso exemplo da realização pulsional na hipercinesia, que pode ocorrer tanto com um endereçamento, buscando afetar e capturar o olhar do outro, como ocorrer no modo autístico, em que se expressa através de automatismos que não entraram no circuito pulsional. 
As formulações que se seguem referem-se justamente a sintomas que se inscrevem no corpo sob a forma de agitação motora, cuja particularidade é se darem a ver, capturarem o olhar do outro e que chamaremos de atos motores, por um lado, para diferenciá-los dos automatismos, e, por outro, por marcarem uma forma de resistência do sujeito em sua singular irredutibilidade.

A inscrição sintomática se dá num corpolinguagem (Costa, 2003), que opera no registro do sentido e daquilo que nele, sendo da ordem do traumático da sexualidade, não entra no campo da significação, sendo então o fora de sentido, que a este último faz resistência.

Lembremos o caráter relacional do corpolinguagem, em que algo que é do sujeito lhe retorna, passando pelo outro/semelhante, para quem se dirigem seus atos e suas palavras. Temos aí que o corpo seria, portanto, um suporte relacional que opera pulsionalmente à medida que constrói bordas, e que, muitas vezes, uma movimentação incessante pode ser uma tentativa de se constituir uma borda, através de formas e limites que informem acerca do corpo, seja por temor de perdê-lo ou porque se encontra indiferenciado. Os comportamentos de risco atestam essa experimentação acerca dos limites espaciais no real do corpo.

Nossa formalização até agora aponta para um sujeito que muitas vezes renuncia ao seu espaço e à apropriação/subjetivação de seu corpo para gozar e servir de objeto de gozo ao Outro. Por outro lado, há um movimento de resistência do sujeito ao Outro e Bergès (1997) acrescenta a isso a noção de que do lado do sujeito haja uma defesa contra a pulsão de morte -, defesa contra o Outro e defesa contra o encontro com o real que a pulsão de morte lança incessantemente. O insondável do sujeito comparece através de seu sintoma como a sua singular articulação desses dois campos.

A aposta da Psicanálise, na contramão dos dispositivos de dessubjetivação, parte da ética do desejo. Não visa a uma adaptação à realidade, sustenta a dissociação entre demanda e desejo, e aponta para o encontro com o real, tendo constatado que o objeto de desejo não existe na realidade e fazendo resistência à instrumentalização do gozo no campo social.

A dimensão alienante dos discursos pode ter como ponto de resistência a posição ético-política do sujeito. Um sujeito que, para evitar o 
encontro com a angústia de sua incompletude - fato dado por sua divisão subjetiva - pode ou não optar por uma escolha que tampone sua angústia através de seu assujeitamento ao discurso e ao desejo do Outro ou da massa.

O sujeito tem a possibilidade de uma escolha ética que sustente seu traço de singularidade através de seu desejo ou a de entregar-se ao imperativo de gozo do Outro num apagamento de sua subjetividade.

\section{REFERÊNCIAS}

Bergès, J. (1997). O corpo e o olhar do Outro. In L. Bergès, Escritos da criança (Vol. 2, pp. 51-65). Porto Alegre, RS: Centro Lydia Coriat.

Bergès, J. (2008). O corpo na neurologia e na psicanálise: lições clínicas de um psicanalista de crianças. Porto Alegre, RS: CMC.

Bergès-Bounes, M., \& Forget, J-M. (Orgs.) (2010). L'enfant insupportable. Instabilité motrice, hyperkinésie et trouble du comportement. Toulose, FRA: Éditions Érès.

Birman, J. (1999). Mal-estar na atualidade: a psicanálise e as novas formas de subjetivação. Rio de Janeiro, RJ: Civilização Brasileira.

Costa, A. M. M. (2003). Algumas reflexões sobre a inscrição da letra. In N. V. A. Leite (Org.), Corpolinguagem: gestos e afeto (pp. 115-124). Campinas, SP: Mercado de Letras.

Diener, Y. (2011). On agite un enfant: L'État, les psychotérapeutes et les psychotropes. Paris, FRA: La Fabrique Éditions.

Foucault, M. (1995). Sobre a história da sexualidade. In M. Foucault, Microfísica do poder (pp. 243-276). Rio de Janeiro, RJ: Graal. (Obra original publicada em 1978)

Gori, R., \& Volgo, M.-J. Del (2009). La santé totalitaire: essai sur la médicalisation de l'existence. Paris, FRA: Flammarion.

Guarido, R., \& Voltolini, R. (2009). O que não tem remédio, remediado está?. Educação em Revista, 25(1), 239-263. Recuperado de http://www.scielo.br/scielo.php?script=sci_ arttext\&pid=S0102-46982009000100014\&lng =pt\&tln $\mathrm{g}=\mathrm{pt}$ 
Hora, A. F, Silva, S., Ramos, M., Pontes, S., \& Nobre, J. P. (2015). A prevalência do Transtorno do Déficit de Atenção e Hiperatividade (TDAH): uma revisão de literatura. Psicologia, 29(2), 47-62. doi: 10.17575/rpsicol.v29i2.1031

Infante, D. P. (2011). Psiquiatria para que e para quem? In J. Jerusalinsky, \& S. Fendrik (Orgs.), O livro negro da psicopatologia contemporânea (pp. 63-72). São Paulo, SP: Via Lettera.

Institut Nacional de la Santé et de la Recherche Médicale (2005) [INSERM]. Trouble des conduites chez l'enfant et l'adolescent (Expertise collective). Paris, FRA: Les Éditions Inserm.

Lacan, J. (1961-1962). L'Identification. Recuperado de https://www.valas. fr/IMG/pdf/S9_identification.pdf

Legnani, V. N., \& Almeida, S. F. C. de (2008). A construção diagnóstica de transtorno de déficit de atenção/hiperatividade: uma discussão crítica. Arquivos Brasileiros de Psicologia, 60(1), 02-13.

Legnani, V. N., \& Almeida, S. F. C. de (2009). Hiperatividade: o "não decidido" da estrutura ou o "infantil" ainda no tempo de infância. Estilos da Clínica, 14(26), 14-35.

Legnani, V. N., Andrade, M. F. de, Cairus, R. C. dos R., Kahn, C. T., Silva, E. A. da, \& Silva, E. A. da (2004). Impasses na construção da noção de alteridade nos processos de subjetivação das crianças com o diagnóstico de transtorno de déficit de atenção e hiperatividade. Anais do Colóquio do LEPSI IP/FE-USP. São Paulo, SP, Brasil, 5. Recuperado de http://www.proceedings.scielo.br/scielo.php?pid=M SCooooooo032004000100059\&script=sci_arttext

Pas de Zéro de Conduite pour les Enfants de Trois Ans. (2006). Recuperado de http://www.pasdeodeconduite.org/appel/

Pereira, M. E. C. (2007, maio). Diagnóstico e alienação, ou “Dr., meu filho é TDAH". Anais do Fórum de linguagem da UFRJ: Clínicas da linguagem. Rio de Janeiro, RJ, Brasil, 3. 
Polanczyk, G. V., Arruda, M. A., Almeida, M., Bigal, M. E., Moura-Ribeiro, M. V., \& Golfeto, J. H. (2010). Saúde Mental e desempenho escolar em crianças e adolescentes brasileiros. Análise dos resultados e recomendações para o educador com base em evidências científicas. In Projeto Atenção Brasil. Ribeirão Preto, SP: Instituto Glia.

Polanczyk, G. V., Arruda, M. A., Querido, C. N., \& Bigal, M. E. (2015). ADHD and mental health status in Brazilian school-age children. Journal of Attention Disorders, 19(1), 11-7.

Polanczyk, G. V., Willcut, E. G., Salum, G. A, Kieling, C., \& Rohde, L. A. (2014). ADHD prevalence estimates across three decades: an updated systematic review and meta-regression analysis. International Journal of Epidemiology, 43(2), 434-442. doi: 10.1093/ije/dyt261

Quinet, A. (2009). Psicose e laço social: Esquizofrenia, paranóia e melancolia. Rio de janeiro, RJ: Zahar.

Rivera, F. B. (2016). La elevada prevalência del TDAH: posibles causas y repercusiones socioeducativas. Psicología Educativa, 22(2), 81-85. doi: 10.1016/j.pse.2015.12.002

Rohde, L. A., \& Ketzer, C. R. (1997). Transtorno de Déficit de Atenção e Hiperatividade. In N. Fichtner (Org.), Transtornos Mentais da Infância e Adolescência - um enfoque desenvolvimental (pp. 106-119). Porto Alegre, RS: Artes Médicas.

Rohde, L. A., Miguel, E. C., Fo , Benetti, L., Gallois, C., \& Kieling, C. (2004). Transtorno de déficit de atenção/hiperatividade na infância e na adolescência: considerações clínicas e terapêuticas. Revista de Psiquiatria Clínica (São Paulo), 31(3), 124-131.

Silva, D. R., \& Albertini, M. R. B. (2016). TDAH entre o global e o singular: incursões a partir da disjunção do corpo infantil. Psicologia Clínica, 28(1), 123-138. Recuperado de http://pepsic.bvsalud.org/scielo. php?script $=$ sci_arttext\&pid $=$ s0103-56652016000100007\&lng $=$ pt \&tlng $=\mathrm{pt}$ 
Thevenot, A., \& Metz, C. (2007). Instabilidade psicomotora ou hiperatividade?: riscos dos deslizamentos dos discursos sobre a psicopatologia infantil. Epistemo-somática, 4(2), 49-61. Recuperado de http://pepsic.bvsalud.org/scielo.php?script=sci_arttext\&p id $=$ S1980-2005200700020000 5

Untoiglich, G. (2006). Consenso de especialistas da área de saúde sobre o chamado "Transtorno por Déficit de Atenção com ou sem Hiperatividade". Correio da appoa, 144, 63-68.

Vorcaro, A. (2011). O efeito bumerangue da classificação psicopatológica na infância. In J. Jerusalinsky, \& S. Fendrik (Orgs.). O livro negro da psicopatologia contemporânea (pp. 219-229). São Paulo, SP: Via Lettera. 